\title{
Mathematical Word-Problems That Require Realistic Answer
}

Kamuran TARıM ${ }^{* a}$, Sıdıka Pınar ÖKTEM ${ }^{\text {a }}$
aÇukurova University, Faculty of Education, Adana/Türkiye

\section{Article Info}

DOI: 10.14812/cufej.2014.011

Article history:

Received 23 June 2013

Revised 17 February 2014

Accepted 27 August 2014

Keywords:

Problem solving,

Real life,

Turkish students,

Word problems.

\begin{abstract}
This study aimed to investigate the Turkish students' problem-solving skills about word problems requiring the consideration of real-life situations and the reasons underlying the unrealistic responses the students gave to these kinds of problems. This study was carried out with 300 students selected by random sampling among the students at 6 th, 7th and 8th grades of elementary schools in Turkey. A problem test which requires realistic responses was administered to these students. Two separate forms were arranged for this problem test given to the students. After the students solved the problem test, totally 60 students, were randomly selected to participate in an interview aiming to investigate the students' thoughts while solving the problems and how they comment on the problem situation. In this study, it was determined that the percentage of the students' level of achievement related with the problems the students had to consider the real-life situations was low. This result can be commented that the students tend to make mathematical operations when they meet a problem in a maths class as they think the problem must have an accurate solution although they find the answer unlogical.
\end{abstract}

\section{Introduction}

Problem-solving is one of the cornerstones of maths teaching. In maths teaching, students learn to solve problems systematically and put their thoughts forth while solving problems. Problem-solving is not a separate subject in mathematics, but a topic requiring integration with all maths topics. This way, students can find new thinking ways and they can learn to be self-confident against the situations with which they are unfamiliar in life. These are necessary behaviors for students to formulate the extractions and put mathematical evidences forth (NCTM, 2000).

Word problems, especially the ones with realistic context, are pretty important in terms of making the newly learned mathematical concepts and the development of the skills meaningful, having the potential to motivate students, improving the skills about where and how to use mathematical knowledge in daily life and at work (Verschaffel, Greer \& De Corte, 2000; Depaepe, De Corte \& Verschaffel, 2010). Recently developed curricula aim to provide the knowledge construction by encouraging the problem-solving about real-life situations (Chacko, 2007). The elementary maths curriculum revised in Turkey in 2005 includes real-life related word problems and supports the realistic approach.

Reusser and Stebler (1997) state that real-life related word problems help students to form new mathematical models and to gain new experiences in this subject. Besides, they claim that those kinds of problems provide a convenient atmosphere for students' language development, reasoning, mathematical development and mutual interaction. In this situation, the word problems also contribute to enable students to transfer the formal mathematical knowledge and skills that they learn at school into their real lives. (Greer, 1997; Verschaffel, Corte \& Vierstraete, 1999). Current questions given to the

\footnotetext{
*uthor: ktarim@cu.edu.tr
} 
students are necessary for them to integrate maths with their real life and to develop the behaviours required to solve the mathematical word problems they might face at school.

Completed studies show that students are not very successful in transferring their mathematical knowledge into their real life situations (Gainsburg, 2008; Xin \& Zhang, 2009; Inoue, 2005). Students mostly consider the mathematics as a course which they benefit from in solving the problems in the exams and which brings them success when they solve the problems quickly. They also believe that applying certain rules and formulas is enough to solve the problems.

It was revealed that even in high school classes considered to have good maths education, students have some fallacies about word problems. Students think that word problems have to solved in a short time, they have only one correct answer or mathematics consists of some rules. These kinds of fallacies might prevent students from solving new or various problems willingly or might make them understand harder. (Ersoy \& Gür, 2004; Soylu and Soylu, 2006; Umay, 2007).

In addition, Reusser and Stebler (1997), Verschaffel, De Corte and Lasure (1994) and Yoshida, Verschaffel and De Corte (1997) state in their studies that students are incompetent in integrating the knowledge they gain from their experience into mathematics they learn at school. A great majority of students try to solve the mathematical problems presented in class by using linear reasoning without thinking through deeply.

Similarly, Greer (1997) claims that although the word problems mean establishing the connection between mathematics learned at school and real life, they do not have realistic structures. According to Greer (1997), these problems seem artificial because they can always be solved (actually, not every problem has a solution), they always contain accurate information and the numbers used in those problems are always numerically "clean". In other words, one of the reasons which underlie the unrealistic responses of students is the disagreement between their school experiences and daily experiences (Inoue, 2005). Inoue (2005) tries to clarify the incorrect answers of students that they give to the word problems using calculation approach without thinking through deeply, clashing between the implementation in maths classes and real life situations and students' adding unexpected realistic comments to some problems.

As a result, some studies were needed on word problem-solving skills which are considered to play an important role in providing the connections between the mathematical concepts and arithmetical operations and in relating the mathematics with the daily life. In this study, it was aimed to investigate the Turkish students' problem-solving skills about word problems which require the consideration of real-life situations and the reasons underlying the unrealistic responses that the students gave to these kinds of problems. In this context, the research question was "What are the students' problem-solving skills about word problems which require realistic responses?" and "What are the reasons underlying the responses that seem unrealistic?"

\section{Significancy}

In this study, it is investigated how the students comment on the problems and what their thoughts behind their solutions are. Therefore, it is aimed to determine whether the students' unrealistic responses arise from their direct transactions -without reasoning- or not, whether these unrealistic responses arise from the problems because they are asked in the context of maths class or not. Also, the study investigates whether the students have some realistic explanations according to themselves behind their unrealistic responses that may seem unrealistic or not. A study like this might help to reveal the approaches of the students towards the problem in the problem-solving process.

Although such problems exist both in the 2005 curriculum and in math books, it can be observed that teachers do not give a place to those points in practice. The students wonder how they will benefit from mathematics in their real lives and sometimes the teachers cannot answer students' questions. 
Even the teachers are sometimes not aware of the practicality of mathematics. This study might make teachers and students become aware of the practical uses of mathematics in real life.

\section{Method}

\section{Research Design}

This research is a survey model involving two steps which are qualitative and quantitative aiming to answer 5 research questions. In the first step of the research, two algebra and five word problems, which requires realistic answers, were asked to group. The variabilities used in this step consist of students' ability to resolve problems with realistic answers in mathematical word problems, gender, level of classes, academic and the content of the problem.

\section{Participants}

This study was carried out with 300 students who were selected by random sampling among the students at 6th, 7th and 8th grades of elementary schools in Turkey. 150 of these students were female and 15 of them were male and 100 students were selected from each level. A problem test which requires realistic responses was administered to these students. Two separate forms were arranged for this problem test given to the students. After the students solved the problem test, totally 60 students, 20 from each level, were randomly selected to participate in an interview aiming to investigate the students' thoughts while solving the problems and how they comment on the problem situation. 30 of these students were female and 30 of them were male. This study was done in state schools and the students come from families belonging to different socio-economic levels.

\section{Procedure}

The participants were informed about the study in the beginning of the data collection process. They were told that their mid-term exams would be graded on a higher degree, so the inventories used in this study were administered by the researcher during their class hours -in three different class hours during three weeks. When needs arouse, participants were instructed by the researcher. The participants were expected to respond to the questions in the inventories in 50 minutes each week. In addition, they were told that they could get the results of the inventories if they wished.

\section{Instrument}

Problem Test. A problem test related to "word problems requiring realistic solution" for the maths class in 6th, 7th and 8th grades of elementary schools was used as a data collection tool. In the problem test, three problems (P1, P2 and P5) developed by Inoue (2002) and two problems (P3 and P4) developed by Verschaffel, De Corte and Lasure (1994) were used after being translated into Turkish. While designing the problems, two separate forms (Form A and Form B) containing 7 problems were composed in order to investigate the content effect. The first two questions of each test were determined from algebra problems and the other five questions were determined from the kind of problems requiring realistic response. Algebra problems were used so as to make students feel themselves as if they were having an ordinary maths examination.

Problems designed for Form A were the ones containing only knowledge. The situation in the problem is presented to have the minimum knowledge through general expression (ambigious goals, see Inoue, 2002, p.23). In the problem statements prepared for Form B, the question is presented as if it is the student's own problem (pragmatic goals, see Inoue, 2002, p.23). Two versions of the same problem designed for two separate forms were given below: 
When we look at the problem's version for Form A, we see that a general expression. "There is reading homework of 160 pages. 20 pages are generally read in 30 minutes for this homework. If somebody starts reading at 10 o'clock in the morning, can s/he finish reading at 2 in the afternoon?" (Form A)

However, in Form B, it is stated that the reader on his/her own reads 20 pages in 30 minutes in order to make the readers feel themselves in the situation of the problem statement. "You have to finish 160 pages for a reading assignment. It generally takes 30 minutes for you to read 20 pages. You start reading at 10 o'clock in the morning and one of your friends asks you if you can go out at 2 o'clock in the afternoon. How would you respond to your friend?" (Form B)

Interview Form. After the students solved the problem test, a clinic interview was done with 60 students randomly selected among the participants. These randomly selected students solved the problems for the second time accompanied by the researcher and the clinic interview was done with them. Questions developed by Inoue (2002) were also made use of while designing the interview questions. During the clinic interview, it was aimed to determine what kind of process the students went through while solving the problem test. For this purpose, five questions were asked to students. The opinions of the students who answered these five questions about the necessity of these kinds of problems in maths classes were also taken. Five questions aiming to reveal the thinking processes of the students during the problem solving were given below. First two questions were asked them to obtain general information about how they approach to the problems at the beginning.

1. Do you think you can benefit from your real life in order to be able to solve this problem? (If, yes) Explain?

2. Did anything that took your attention or made you think occurred while solving the problem?

The answers to these questions give us clues about how the students comment on the problems during problem-solving process. After the students answered these two general questions above for all of the problems, the questions below were asked to them for each problem.

3. If you had experienced a situation like the one in the problem, would you have behaved like the way you did in problem-solving in your real life? Why? (If, yes) Do you think your solution is appropriate for real life? It does not seem as appropriate, what do you think of this situation? Why did you answer like this?

The answers to these questions showed us if the students establish a relationship between the problem context and the real life while solving the problems or not. In other words, the answer to the question of "would s/he behave the same way if $s /$ he faced with a similar situation in real life" was investigated.

At the same time, the answers to these questions provided some information about if the students think about the problem situation or not and what kind of explanations they made about the problem. In other words, the question of "Do the answers of the students really originate from their ignoring real life situations or having different realistic comments according to themselves?" was tried to be explained.

4. Did you think of realistic solutions during problem solving? (If, yes) Why didn't you write it on the paper?

This question aimed to determine if the student needed to calculate as the question was asked in maths class although s/he was aware of realistic responses. In other words, the answer of this question showed us if the student needed to calculate as the question was asked in maths class although s/he was aware of realistic responses. 
5. After the students answered these questions, their thoughts about the benefits of math at school and the usage of word problems that require realistic responses in math classes were asked.

\section{Data Collection}

The data of this study was collected during 2007-2008 academic year. Quantitative data was collected from 300 students at 6th, 7th and 8th grades of elementary schools. After the students were given a problem test of 7 questions in the classroom, they were asked to answer the questions in 40 minutes and write their solutions in a detailed way. After the completion of problem test individually, 60 students were randomly selected to have a clinic interview. During these interviews, the students who solved all problems for the second time under the supervision of the researcher were interviewed for about 45 minutes.

\section{Data Analysis}

The quantitative data collected in this research was analysed by descriptive statistics and the qualitative data collected during the clinic interviews was analysed by content analysis. While assigning problem solving codes based on the criteria -if the students used calculation approach, if they gave responses appropriate for the maths class although they knew the realistic responses, if the responses reflect the reality and distinguishing if the students understood the structure of the problem situation-, the data coding system developed by Inoue (2005) was used:

1. Wrong or blank answer (WA): This was coded when unrelated responses were given, random operations with the numbers in the problem were done or no response was given.

2. Answers based on an operation (OA): This code showed that the students solved the problems by calculating only with the numbers and by believing that the result they would reach would be useful in the real life.

3. Realistic answer (RA) : This code contains answers that the students gave based on operation and the ones that the students gave by adapting the result into the real life after solving the problem.

4. Conformist Answer (CA): This was coded when students told that they felt compulsory to make calculations as they were in a maths class although they thought of appropriate answer for the real life.

5. Private Comments (PC): This was coded when the answers of the students seemed like an answer based on operation but when it was understood from the interviews that they gave reasonable answers in fact.

During the coding, the grade levels, the gender and the levels of success of the students and the group of problem test they solved during the implementation were considered. The list of codes used in the analysis is given in Table 1. 
Table 1. The list of codes used in the analysis

\begin{tabular}{|c|c|c|c|c|c|c|c|c|c|}
\hline \multicolumn{3}{|c|}{$\begin{array}{l}\text { Grade } \\
\text { levels } \\
\text { of } \\
\text { classes }\end{array}$} & \multicolumn{2}{|c|}{$\begin{array}{c}\text { Group of problem } \\
\text { test }\end{array}$} & \multicolumn{3}{|c|}{$\begin{array}{l}\text { Students' achievement level } \\
\text { in maths (according to the } \\
\text { grades they got in maths class } \\
\text { in previous semester) }\end{array}$} & \multicolumn{2}{|c|}{$\begin{array}{l}\text { Gender of the } \\
\text { students }\end{array}$} \\
\hline 6 & 7 & 8 & $\begin{array}{l}\text { A } \\
\text { It contains } \\
\text { knowledge }\end{array}$ & $\begin{array}{c}\text { B } \\
\text { It } \\
\text { contains } \\
\text { person }\end{array}$ & $\begin{array}{c}\mathrm{H} \\
\text { Students } \\
\text { with } \\
\text { high } \\
\text { success } \\
\text { in maths }\end{array}$ & $\begin{array}{c}\text { A } \\
\text { Students } \\
\text { with } \\
\text { average } \\
\text { success } \\
\text { in maths }\end{array}$ & $\begin{array}{l}\text { L } \\
\text { Students } \\
\text { with low } \\
\text { success } \\
\text { in maths }\end{array}$ & $\begin{array}{c}\text { M } \\
\text { Male }\end{array}$ & $\begin{array}{c}\mathrm{F} \\
\text { Famale }\end{array}$ \\
\hline
\end{tabular}

For example; 6. A-L-F - 1 means the first female student with low success in maths who solved Form A of problem test that contains knowledge.

\section{Results}

\section{Findings Related with Quantitative Data}

In this section, the findings related with the skills of students, who participated in this study, at the secondary part of elementary schools about their problem solving skills on the word mathematical problems requiring realistic responses are presented.

Table 2 shows the distribution of answer types that the secondary level students gave to mathematical word problems requiring realistic responses regarding gender. As seen in Table 2, $18.6 \%$ of the answers that the students gave to the problems requiring realistic answers is wrong or black. When the answers of the students who participated in this study were considered, it was found that a large percentage of the answers (62.9\%) consisted of operation-based answers (direct calculation). The students produced realistic answers at the rate of $14.7 \%$ and answers that were both operation based and realistic in the rate of $3.8 \%$.

Table 2. The Distribution of the answer types according to the gender

\begin{tabular}{|c|c|c|c|c|c|c|}
\hline & \multicolumn{4}{|c|}{ GENDER } & \multirow{2}{*}{\multicolumn{2}{|c|}{ TOTAL }} \\
\hline & \multicolumn{2}{|c|}{ FEMALE } & \multicolumn{2}{|c|}{ MALE } & & \\
\hline & $f$ & $\%$ & $f$ & $\%$ & $f$ & $\%$ \\
\hline \multicolumn{7}{|c|}{ Answer Types } \\
\hline WA & 145 & 9,7 & 134 & 8,9 & 279 & 18,6 \\
\hline $\mathrm{OA}$ & 468 & 31,2 & 475 & 31,7 & 943 & 62,9 \\
\hline RA & 100 & 6,7 & 121 & 8,1 & 221 & 14,7 \\
\hline AOR & 32 & 2,1 & 25 & 1,7 & 57 & 3,8 \\
\hline Total & 745 & 49,7 & 755 & 50,3 & 1500 & 100 \\
\hline
\end{tabular}


As seen, the total rate of using realistic approaches (RA and AOR) in answering the problems was $18.6 \%$. The result did not seem different when the answers to the same problems were analyzed according to the gender of the students. The highest rate among the female students with the percentage of 31.2 and among the male students with the percentage of 31.7 belonged to the operation based answers when the answers of both female students and male students were taken into account. Although the difference was not a big one, the percentage of male students' giving operation based answers to the problems was higher than the female students'. While the percentage of female students' giving realistic answers was 6.7, the male students' was 8.1. The percentage of using both operation based and realistic approach in solving the problems was only 2.1 among the female students and 1.7 among the male students. In other words, the percentage of approaching to the problems in a realistic way (RA and AOR) was 8.8 among female students and 9.7 among the male students. The percentage of the male students' using realistic approach was higher than that of the female students'.

The distribution of the answer types according to the grade levels of students who participated in the study is shown in Table 3.

Table 3. The distribution of the answer types according to the grade levels

\begin{tabular}{|c|c|c|c|c|c|c|c|c|}
\hline & \multicolumn{6}{|c|}{ GRADE LEVEL } & \multirow{2}{*}{\multicolumn{2}{|c|}{ Total }} \\
\hline & \multicolumn{2}{|c|}{6} & \multicolumn{2}{|c|}{7} & \multicolumn{2}{|c|}{8} & & \\
\hline & $f$ & $\%$ & $f$ & $\%$ & $f$ & $\%$ & $f$ & $\%$ \\
\hline \multicolumn{9}{|c|}{ Answer Types } \\
\hline WA & 122 & 8,1 & 112 & 7,5 & 45 & 3,0 & 279 & 18,6 \\
\hline OA & 327 & 21,8 & 286 & 19,1 & 330 & 22,0 & 943 & 62,9 \\
\hline RA & 55 & 3,7 & 63 & 4,2 & 103 & 6,9 & 221 & 14,7 \\
\hline AOR & 11 & 0,7 & 14 & 0,9 & 32 & 2,1 & 57 & 3,8 \\
\hline Total & 515 & 34,3 & 475 & 31,7 & 510 & 34,0 & 1500 & 100 \\
\hline
\end{tabular}

As clear in Table 3, the lowest percentage of giving wrong answers (3\%) belonged to the 8th grade level. Similarly, 8th graders gave the most answers based on operation (22\%). The percentage of the students who gave realistic answers and answers both operation-based and realistic increased from the 6 th grade level to 8 th grade level gradually. That is, the percentage of giving realistic answers increases in direct proportion to the grade level. This can be resulting from students' thinking about the problem solutions in a more detailed way and their abilities in adapting real life knowledge into the problem solving more easily when their grade levels increase.

The distribution of the answer types according to the students' level of achievement in maths was shown in Table 4.

It can be seen in Table 4 that most wrong answers (11.5\%) belong to the students with low success. While the percentage of giving wrong answers decreased inversely proportional with the success, middle achievers in maths gave operation-based answers more (24.7\%). As seen in Table 3 , the percentage of the low achievers in maths who gave realistic answers (RA and AOR) to these problems was 3.2; whereas, the percentage of middle achievers in maths who gave realistic answers (RA and AOR) to these problems was 6.5 and the percentage of high achievers in maths who gave realistic answers (RA and $A O R$ ) to these problems was 8.9. Namely, the percentage of giving realistic answers increases in direct proportion to level of achievement. This can be resulting from high achievers' thinking in a more detailed way on the problem solutions. 
Table 4. The distribution of the answer types according to the students' level of success in maths

\begin{tabular}{|c|c|c|c|c|c|c|c|c|}
\hline & \multicolumn{6}{|c|}{ The level of achievement in maths } & \multirow{2}{*}{\multicolumn{2}{|c|}{ Total }} \\
\hline & \multicolumn{2}{|c|}{ Low } & \multicolumn{2}{|c|}{ Average } & \multicolumn{2}{|c|}{ High } & & \\
\hline & $f$ & $\%$ & $f$ & $\%$ & $f$ & $\%$ & $f$ & $\%$ \\
\hline \multicolumn{9}{|c|}{ Answer Types } \\
\hline WA & 172 & 11,5 & 87 & 5,8 & 20 & 1,3 & 279 & 18,6 \\
\hline OA & 270 & 18,0 & 371 & 24,7 & 302 & 20,1 & 943 & 62,9 \\
\hline RA & 40 & 2,7 & 79 & 5,3 & 102 & 6,8 & 221 & 14,7 \\
\hline AOR & 8 & 0,5 & 18 & 1,2 & 31 & 2,1 & 57 & 3,8 \\
\hline Total & 490 & 32,7 & 555 & 37,0 & 455 & 30,3 & 1500 & 100 \\
\hline
\end{tabular}

The distribution of the answer types that the students gave to the problems according to the content of the problem was shown in Table 5 . When Table 5 analyzed, it is seen that including the person into the problem affects the solution of the problem positively. The percentage of the wrong answers in the problems containing the person decreased to $9.1 \%$ from $9.5 \%$ when compared to the problems containing information and the percentage of the operation-based answers decreased to $31 \%$ from $31.9 \%$. The percentage of the realistic answers increased to $7.8 \%$ from $7 \%$ and the percentage of both operation-based answers and realistic answers increased to $2.1 \%$ from $1.7 \%$. Therefore, the percentage of thinking about the realistic answer (RA and AOR) on the problems containing information was 8.7; whereas, the percentage of thinking about the realistic answer (RA and AOR) on the problems containing the person was 9.9. This result shows that student achievement is affected positively by the problems' containing the person, but not in a big rate.

Table 5. The distribution of the answer types given to the problems according to the content of the problem

\begin{tabular}{|c|c|c|c|c|c|c|}
\hline \multicolumn{7}{|c|}{ The content of the problem } \\
\hline & \multirow{2}{*}{\multicolumn{2}{|c|}{$\begin{array}{c}\text { Group A } \\
\text { Containing } \\
\text { information }\end{array}$}} & \multirow{2}{*}{\multicolumn{2}{|c|}{$\begin{array}{c}\text { Group B } \\
\text { Containing the } \\
\text { person }\end{array}$}} & \multirow{2}{*}{\multicolumn{2}{|c|}{ Total }} \\
\hline & & & & & & \\
\hline & $f$ & $\%$ & $f$ & $\%$ & $f$ & $\%$ \\
\hline \multicolumn{7}{|c|}{ Answer Types } \\
\hline WA & 142 & 9,5 & 136 & 9,1 & 278 & 18,5 \\
\hline OA & 478 & 31,9 & 465 & 31,0 & 943 & 62,9 \\
\hline RA & 105 & 7,0 & 117 & 7,8 & 222 & 14,8 \\
\hline AOR & 26 & 1,7 & 31 & 2,1 & 57 & 3,8 \\
\hline Total & 751 & 0,1 & 749 & 49,9 & 1500 & 100 \\
\hline
\end{tabular}




\section{Findings related with qualitative data}

Findings related with personal comments of the students they made during problem solving. The distribution of the answer types that 60 students who were interviewed gave to the problems was shown in Table 6.

As seen in Table 6, $25 \%$ of all answers given during the interviews with 60 students was realistic. Only $3.6 \%$ of $75 \%$ gave wrong answers. Even if it was considered that the rest $71.4 \%$ gave unrealistic answers, in other words operation-based answers, it was found in the clinical interviews that the students made personal comments on the problem solution in the $11.6 \%$ of these answers. $18.3 \%$ of the students gave conformist answers to the problems. That is to say, the students stated that they preferred to use the direct calculation way as those problems were asked in a maths class although they thought about some realistic solutions in fact.

Table 6. The Distribution of the answer types

\begin{tabular}{|c|c|c|c|c|c|c|c|c|c|c|c|c|}
\hline & \multicolumn{10}{|c|}{ ANSWER TYPES } & \multicolumn{2}{|c|}{ Total } \\
\hline & \multicolumn{2}{|c|}{ WA } & \multicolumn{2}{|c|}{$\mathrm{AO}$} & \multicolumn{2}{|c|}{ RA } & \multicolumn{2}{|c|}{$\mathrm{CA}$} & \multicolumn{2}{|c|}{ PC } & & \\
\hline & $f^{-}$ & $\%$ & $f$ & $\%$ & $f$ & $\%$ & $f$ & $\%$ & $f$ & $\%$ & $f$ & $\%$ \\
\hline $\begin{array}{l}\text { Bus station } \\
\text { problem }\end{array}$ & 1 & 0,3 & 24 & 8 & 6 & 2 & 21 & 7 & 8 & 2,6 & 60 & 20 \\
\hline $\begin{array}{l}\text { Reading } \\
\text { Problem }\end{array}$ & 4 & 1,3 & 30 & 10 & 6 & 2 & 18 & 6 & 2 & 0,6 & 60 & 20 \\
\hline $\begin{array}{l}\text { Party } \\
\text { Problem }\end{array}$ & 0 & 0 & 31 & 10,3 & 17 & 5,6 & 11 & 3,6 & 1 & 0,3 & 60 & 20 \\
\hline $\begin{array}{l}\text { Board } \\
\text { Problem }\end{array}$ & 3 & 1 & 28 & 9,3 & 9 & 3 & 5 & 1,6 & 15 & 5 & 60 & 20 \\
\hline $\begin{array}{l}\text { Picnic } \\
\text { Problem }\end{array}$ & 3 & 1 & 11 & 3,6 & 37 & 2,3 & 0 & 0 & 9 & 3 & 60 & 20 \\
\hline Total & 11 & 3,6 & 124 & 41,3 & 75 & 25 & 55 & 18,3 & 35 & 11,6 & 300 & 100 \\
\hline
\end{tabular}

The answers of some students who gave conformist answers to the problems are as follows:

"It does not work when we write like that. They want clear answers from us in maths." (6. A-H-F - 2)

"Shall we write these? But we follow a mathematical way in the exam. We are already used to doing it." (6. A-H-M - 1)

"I had thought some of them. But I did not write them because I did not know that we could answer them according to the daily life. If you had informed me that I could answer according to the real life, I would write them." (7. A-Y-E - 1)

"I did not solve them on logical way, but on operation. I mean, I did not think that these might happen in real life. I did like that because it was an exam. It was the first time in my life I solved a test which was unreal in fact." (6. B-H-F-4)

When the students' answers were considered, it could be said that they were pushed to give answers based on operation as the problems were asked in a maths class although they were aware of the realistic answers. The students reported that they thought there was an accurate answer of the mathematical problems and they felt obliged to answer the problems according to that fact.

The board problem is the one on which most personal comments were made. Most of the students' answers were that they knew there were half-meter remainders from each block, they could stick and 
combine those half-meter remainders and obtain two more blocks. Some personal comments made for this question are as follows:

"I would stick the rest in the board problem." (8. B-H-F - 1)

"I can have two one-meter from each and it totally makes 8 . If I combine those half-meters, it totally makes 10." (6. A-A-M - 1)

The picnic problem was another problem which seemed false at the beginning but then which was revealed after the interviews that the students thought about the realistic answers according to them. The students made three different comments according to themselves about this problem. The first of these answers was 11. They thought that the students could go on their feet on the buses or they could be distributed to other 11 buses and could go in a cramped way. Some part of the students who stated that the problem could not be solved supported that the students could not go on the trip without a teacher and the number of teachers and parents who would accompany the students on the trip should have been indicated. One of the students explained that he didn't mean that the bus was half but he meant half of the bus could become full by saying $11 \frac{1}{2}$ buses. Some personal comments made for this problem are as follows:

"In the picnic problem, I thought the teachers, the director and the parents would also come." (7. B-Y-K 3)

"In the picnic problem, the remained students could be distributed to other buses." (6. A-L-M - 1)

"By saying $11 \frac{1}{2}$ buses, I meant that the half of the last bus could become full." (7. B-L-F - 2)

"Do we take remained 40 people by another bus? Do we need to?"( 7. B-L-F -1)

For the solutions, the bus station problem is the third one on which most comments were done. Some of the comments for this problem are as follows:

"Then, I would leave earlier and arrive on time." (8. B-H-M - 2)

"We can have problems on the way, itself. There might be heavy traffic or construction. However, I would get the time that I lost here back by increasing my speed. I would say that I would arrive on time. I would say that I would arrive early for my friend." (8. B-L-M - 2)

"He might have to stop at the red lights or he might not, he might go through the green wave." (7. B-L-F -1)

"For example, there might be heavy traffic. He might have to stop at the red lights. Personally, I would go faster." (8. B-H-M - 1)

"I thought it was an area closed to the traffic as it was a maths problem." (6. B-A-M - 3)

Among the other solutions, some of the answers which contain personal comments are as follows.

"I can read in fact. I wouldn't go out except from going to the washbasin. I would compensate this." (6. B-A-M - 2)

"There might be some problems but if we adhere to our plan, these problems might disappear.

"We can reach at a time close to that. In fact, it might be necessary for their needs. We can assume that they only wanted to read a book then." (7. A-Y-E - 2)

"I would say that I would leave for the problem about reading. I am a kind of person who likes reading books and I can read even faster. When I had needs, I would call my mother. I do not feel hungry in any case." (8. B-H-F-1) 
"The bus might be late. I would not be able to reach on time because nothing can be known before it happens but I would call in a case like this. If I go there to pick him up, it means that he is a kind of person that can understand my situation. Or else, why will I pick him up?" (8. B-L-M - 1)

The findings related with the student's perception about the problem. The findings related with the questions which were asked by the researcher to the students during the clinical interviews are presented below.

1. During interview firstly it is asked that if they have taught of making use of real life situations while solving the problems. While $13 \%(8 / 60)$ of the students who were interviewed stated that they did not make use of real-life because they did not think they could make use of it, the other $13 \%(8 / 60)$ indicated that they could make use of real-life but they did not. $55 \%(33 / 60)$ of the participants stated that they made use of real-life in some problems, and $18 \%(11 / 60)$ of the participants stated that they made use real-life in all of the problems.

The answers of the students who did not think they could make use of real-life or did not write although they thought they could make use of are as follows:

"I did not think about them so much because they were not so effective in problems." (6. A-H-F - 2)

"I thought about them but I did not write them here. Because these were just exam questions. Even if he arrives at the bus station exactly at 9 , he will be late. But I did not write this here as this was a maths exam." (6. B-H-M - 2)

"Yes. I thought about the time and break but I did not write here. But things like breaks or something are not written in maths. Generally, it is thought as a non-stop journey. However, it would be possible if a five-minute break was mentioned. There could be traffic jam." (7. A-A-M- 2)

"It becomes wrong if it is like that." (8. B-H-M - 1)

The student coded as 7. B-H-F - 2 found the solution as 5 hours to go to the bus station in the first implementation but as five hours was end to end, he told that he added one hour more not to be late for the bus. The student declared that the way he followed was more realistic and he approached to the problem logically in the first implementation but in the second implementation he approached to the problem in a mathematical way and made mathematical operations.

Some part of the students who said that they made use of real-life while solving the problems told they really thought about the situations that are possible in real life. On the other hand, some part of the participants told that they made use of real-life situations without considering the possible problems in the real life. For example, the following answer of the student coded as 8. A-A-F - 2 shows that she considered the possible problems in the real life;

"I made use of possible real life situations in some of these problems. For example, he could arrive on time in reading and bus station problems but his reading might become slower in the reading problem if he reads without giving breaks so it is possible not to finish on time."

However, the following answer of the student coded as 6 . A-H-F - 3 shows that although she told that she made use of real life, she did not consider the possible problems in real life in fact;

"Well, we make use of real life situations. I made my calculation. If he goes 60 kilometers in an hour, he finishes $\mathbf{3 0 0}$ kilometers in five hours. It is also the same in real life. I said he could arrive on time."

2. It is asked that if there are any points which attract attention in the problems. The students ( $38 \%)$ told that there were not some situations that took their attentions; however, $62 \%$ of the students told that there were some situations that took their attentions. Two of the students found situations that took their attentions in the bus station problem, 4 of them found in the reading problem, 15 of them found in the party problem, 6 of them found in the board problem and 12 of them found in the picnic 
problem. The students found the party problem and the picnic problem most confusing. Some of the students' comments about the party problem are as follows:

"Here some situations attracted my attention. If the friends are partners, both of them inform these five people. As Arda calls a different person, 6 people come. 6 people come instead of 10 people. If their friends are different people so 11 people come." (7. A-A-M - 1)

All of the students who had difficulty in the picnic problem emphasized that the remainder in the division made them confused. The answers of these students are as follows:

"Yes, for example, I tried to solve the picnic problem both in the first implementation and now. I could not solve it. The result was not accurate. 11 buses are completely full. There are 40 people left, and then it becomes 12 buses. If the result has a difference, we skip the problem because we think it is a wrong problem. In order to make this problem be solved, the result must be accurate." (7. B-H-F - 1)

"In the picnic problem, I thought if the director or the teacher would come to the picnic or not." (8. B-H$M-2)$

Two of the students who were confused in the board problem stated that they were confused because the width of the board was not given. The other four students who were confused in the board problem stated that they hesitated if they would combine the remainder half-meter. The answers of two students are as follows:

"The width of the boards must be given to me. Otherwise, I create too many from this. The width of the boards must be known. I can create a lot of." (8. B-H-M - 1)

Some of the participants made comments about all of the problems.

"Yes. All the answers to the questions of "Can he reach?" or "Can he finish?" were positive." (6. A-H-M 2)

Some of the participants stated that they found the presentation of the problems different.

"I was asked questions like these and they were strange. They were not like maths questions. Some questions were like "What would you tell to your friend?"” (7. B-L-F - 3)

3. Students have been questioned whether they would give the same answer in case of facing similar problems in their real life. Moreover, if their answer is yes they have been asked if it is always acceptable in real life. Thirty-four students (57\%) told that they would have given the same answer if they had seen these problems. 23 students $(38 \%)$ told that the process would not be the same in the real life. While the rest 2 students ( $3 \%)$ gave realistic answers to all of the questions, 1 student ( $2 \%)$ was indecisive.

The answers of the participants who told that they would not have given the same answers in reallife are as follows:

"Even if he arrives at the airport exactly at 9, he will go in and will be late but I did not write this here as this was a maths problem. It takes some time to get ready and go down when he finishes reading the book. For the party problem, as we were both friends each other, are we included in those friends? I think this is a tricky question." (6. B-H-M - 2)

"No. It is not certain for us to reach there. There might be some problems. For example, they might have some needs in the reading problem but there should not be needs as it is a maths problem. In the party problem, they should have expressed that the students had some friends in common. They did not express this. There was a remainder in the bus problem; there should have been an accurate result." ( 7 . A-H-F - 1)

The students who gave unrealistic answers and who told they would have given the same answer if they had seen the same problem in the real life were asked if their solutions would also work in the real 
life. After the students who insisted that their solutions would always work in the real life were informed that their solutions might not always work in the real life, all of the students became aware of possible problems when they were asked what might happen for these situations in the real life. The answers of some students who later became aware of the realistic restrictions are as follows.

"We wait for some time if we face some obstacles. We wait for half an hour maximum." (6. B-L-M - 1)

"Emre and Arda are friends as they give a party together, maybe they call their friends from their classrooms. The result changes then. For the bus station problem, anything can happen about traffic. There might be some problems." (6. A-A-F - 1)

"In fact, another bus is needed for the students left. There might be traffic jam. There might have been an accident. He might get bored while reading books. He might need something. The friends who Arda and Emre invited to the party might bring some other friends along with them." (6. B-H-F - 2)

4. It has been asked if students take into consideration those real life situations while solving the problems and if yes why they would not note this in their answer sheet. Thirty of the students $(50 \%)$ who gave unrealistic answers to at least one problem stated that they did not think of realistic ideas while solving the problems. 28 of them (47\%) said that they thought of realistic ideas that they mentioned after they solved the problem while solving the problems. The rest 2 of the students ( $3 \%)$ gave realistic answers to all of the problems.

When the students who thought about the realistic answers in any of the problems but did not write them on the answer sheet were asked why they had not written the realistic answers on the answer sheet, they stated that they did not write the realistic answers as a problem in a maths class must generally have a mathematical solution.

"Yes, I thought about the time and the break but I did not write this. Breaks are not written in a maths class. It is considered as a non-stop journey. But if they had mentioned about a five-minute break, it would have been possible." (7. A-A-M - 2)

"It does not work when it is written like that. We are supposed to give accurate answers in maths." (6. A-H-F - 2)

"I thought about the party problem but not about the others. Were we supposed to write those? But we follow the mathematical way in the exams. We are used to doing it." (6. A-H-M - 1)

"Yes. You know you can do it. Because teachers always ask similar questions. You think there is an accurate answer of that problem." (7. A-A-M - 5)

Seven of the participants (12\%) stated that they did not consider the possible problems because they believed that those kinds of problems should have been written in parenthesis.

"I thought about these but I did not write them because I thought they were not necessary. They did not want anthing like this from us. If there had been an explanation about this, I would have written what they wanted. If there had been an explanation that the students had some friends in common, I would have considered this." (6. B-H-F - 3)

"They had not written those, they had not said that they would give a half-minute break. Normally, we should think about the problems superficially. I always make mistakes when I think about the details. We get different results when we go into details but this result is always true." (46 8. A-H-M - 1)

"I thought about this but I did not need to write as the questions were not asked like that. They should have expressed if something like that would happen." (6. B-L-M - 1)

When the students who gave realistic answers to all of the problems were asked what the factor which made them think about the realistic answers was by informing them that most of their friends did not think about the realistic answers but they, themselves, gave realistic answers to all of the problems; 
"That is to say, I calculate in the other way, and then I think that both ways are possible. In some of the questions we see, it is said that it is neglected so we directly use mathematical operations. But here there is not anything like this; I understood that there was not a certainty so I gave answers like this. In fact, we study according to the examination system. In the exams, there are 4 choices and there must be an accurate answer. However, these are open-ended questions. We are not asked open-ended questions in our exams. I would do the same if I see questions like these." (8. B-H-F - 1)

"I would not give answers like this in class or in exam but I did not see any inconvenience as the questions were not graded. (8. B-H-F - 2)

5. As a last question it has been questioned if the students learn these mentioned before and if they see examples of real life situations such as traffic lights and what they think about learning in this way in their classes. When the participants who were interviewed were asked if realistic situations were taught in classes, $85 \%$ of them told that those situations were taught in classes and $15 \%$ of them told that those situations were not taught in classes. When this question was asked, it was seen that $30 \%$ of the 6 th graders told that those situations were taught, $10 \%$ of 7 th graders told that those situations were taught and $5 \%$ of the 8 th graders told that those situations were mentioned in classes. It can be said that the explanation of real-life situations decreases while the grade levels increases.

The answers of the students who told that those situations are taught in class are as follows:

"Yes, it is explained. It did not come to my mind as it is not explained so often." (6. A-L-F - 1)

"Sometimes, some examples are given but not to express this for the hell of it." (6. B-H-F - 4)

As seen, the students who told that those situations were taught in class said that those situations were seldom explained. Some sample answers of the students who told that those situations were not taught in classes are given below.

"No, they are generally used to make jokes or something in class." (6. A-H-M - 1)

"No. As we solve the problems mathematically, we consider the questions directly in that perspective." (7. B-H-F - 3)

"For example, we tell the teachers about those. The teachers say that they do not take those into account. We assume that there is nothing. How can I know that there are traffic lights on the way to the bus station?" (8. B-H-F - 2)

When the students who were interviewed were asked the question "Should these kinds of problems be used in classes?" $33 \%$ of them stated that these kinds of problems should not be used in classes and $63 \%$ of them stated that they should be used. The rest $5 \%$ of the students were indecisive. $53 \%$ of female students and $70 \%$ of male students declared that these kinds of problems should be used in classes. When the answers are analyzed according to the grade levels, it is seen that $65.7 \%$ of the 6 th graders, $70 \%$ of the 7 th graders and $50 \%$ of 8 th graders implied that these kinds of problems should be used in classes; however, when the answers are analyzed according to the level of achievement, it is seen that $85 \%$ of the students with low success, $68 \%$ of the students with average success and $48 \%$ of the students with high success expressed that these kinds of problems should be used in classes. As seen, the percentage of the students who support the usage of these kinds of problems in classes decreased among the 8th graders and the students with high success. This might be why the 8th graders focus on the upcoming examination and the students with high success find these kinds of implementations unnecessary and think they are time consuming in classes. Besides, it can also be said that the students with low success will enjoy the classes more and will like mathematics more through these kinds of problems.

The answers of some participants who find these kinds of problems unnecessary are as follows: 
"It should not be taught. Consequently, they will not be used in the examinations as the result would be different then. Now, maybe the classes are not exam-oriented but all private courses are exam-oriented. Because of that, it should not be taught." (6. A-H-F - 2)

"If it is taught, it will be very confusing. I think it should not be taught. I already learn it in real-life; teachers do not need to teach it. It is enough if the teachers give us the formulas." (7. A-A-M - 1)

"In fact, they should not be taught. Everything might happen. Nobody can find the answer.

"We need mathematics to live and to pass the exams. We already use maths to balance the budget. This is social life. Mathematics is a virtual life. They are different from each other. The teacher does not say they never take place in exams." (7. A-H-M - 2)

The student coded as 8 . B-H-F -2 who supported that they should not be taught in classes answered as follows;

"When the teachers asks questions like these, my friends immediately blurt out as "we can not go there in five hours, we can not reach to the bus station". This is seen as a disruption of the class. We already know those, we do not need to see them again. Mathematics is a different world; the real-life is a different world. If it had not been like that, our teacher would not have answered us as "we do not present them to you not to use them in real-life, to use them in maths exams" when we wanted to know the reason why we are taught the possibility in maths class. If we see them just for OKS, it means that we will not benefit from them in real-life."

As it is seen, the students who think that the problems should not be solved appropriate to the real life told that if they solve the problems in this way, they will get confused and will not be able to find the accurate result. They also supported that this might be reason to fail in the examination as it is a multiple choice test.

The answers of some students who think that realistic situations should be used in maths classes are as follows:

"They should be explained. We might approach to the problems in different ways. In fact, I did not think that math and real-life were related with each other. " (6. B-A-M - 1)

"In fact, they should be taught as they can also be implemented in real-life. It is already impossible without any obstacles. We never take possibilities into account as if we will never get tired." (6. B-H-F 4)

"Definitely. It would be more exciting, I would like more. I would concentrate on the lesson better." (7. B-L-F -1)

"In my opinion, they should be taught. In fact, I think about them, they come to my mind but I do not ask to my teacher. If I ask, I know the reaction of my teacher. The teachers find them unreasonable and they think we are making fun." (7. A-O-E - 5)

The comments of the students show that these kind of realistic situations are not taught in classes, and it is considered as a disruption to the class if they are explained or asked.

\section{Discussion, Conclusion \& Implementation}

In this study, it was determined that the percentage of the students' level of achievement related with the problems that the students had to consider the real-life situations was low. In addition to this, some results showing that the students have strong tendencies in approaching to the word problems presented in maths classes in an unrealistic and calculating way were obtained. These results are consistent with many studies carried out abroad (Verschaffel, De Corte \& Lausure, 1994; Reusser \& 
Stebler, 1997; Greer, 1997; Yoshida, Verschaffel \& De Corte, 1997; Cooper \& Harries, 2002; Inoue, 2002; Palm, 2008)

When the answers given to the same problems were analyzed in terms of content, it was seen that the content of the problem affects the solution of the problem, but not largely. This result that shows similarity with the findings obtained by Inoue (2002) and Palm (2008) indicates that the problem's containing the person affects the solution of the problem positively. Palm (2008) expressed that the percentage of giving realistic answers increases substantially by changing the text of the problem.

Nearly half of the students who did not give realistic answers to at least one problem told that they thought about these kinds of realistic situations while solving the problem but did not write them on the answer sheet. $60 \%$ of the students who thought about the realistic answers but did not write them on the answer sheet pointed the reason as the problems' being asked in math classes. This result can be commented that the students tend to make mathematical operations when they meet a problem in a maths class as they think the problem must have an accurate solution although they find the answer unlogical. $21 \%$ of the students explained the reason why they did not write their realistic opinions with the statement of "If possible problems in the real life are needed to consider, they must be written in paranthesis", and they supported that possible problems in the real life must be stated when they are asked in a maths problem; otherwise, it will be meaningless to think about those possible problems. As Ersoy and Gür (2008) indicated both the teachers and the students see the problem solving as an activity which improves their calculating skills. Besides, they expressed that an important part of the teachers do not mind the way the students follow while solving the problem but rather they take into consideration the correct answer. Consequently, this result can derive from the perspectives of teachers and students towards problem solving and the students' not being able to harmonize the real life and the mathematics.

Another result obtained in this study is that $38 \%$ of the students stated that they would not give the same answer if they saw these kinds of problem in their real lives. These students who thought about realistic situations in the problems but did not write them told that the mathematical problems can not be solved in this way. The students indicated that they used the same approach while solving these problems as they make operations to solve them in their math classes. Even some of the students especially emphasized that the real-life and the mathematics are totally different from each other and the mathematics is abstract.

The students (57 \%) expressed that they would the give same answer if they saw these kinds of problems in their real lives. In other words, these students seem sure that their solutions are right and those solutions will always work. These results can be commented that the inefficiency of students in solving these kinds of problems is related with their habits and beliefs. At the end of the interviews, it was seen that many students approach the word problem superficially, look at the problems generally without making reasoning and they focus on making operations. Some part of the students think that word problems are not totally related with reality or only a bit related with it and accept that everything needed to solve the problem is given within the problem itself. The reason underlying a part of these habits and beliefs can be identified as a system consisting of certain rules and expectations established between the teacher and the student at school. It was seen that most of the students did not use solutions in which they must consider their real-life situations themselves related with the problem solving activity. Even it was determined that some parts of the students do not trust these kinds of solutions and think that they might make them to solve problem in a wrong way. This result can be resulting from their teachers' not taking the real-life situations into consideration while solving these kinds of problems at school. Besides, this can be because the students did not understand the necessity of the real-life situations in problem solving. These results show similarities with the results of De Bock, Dooren, Janssens and Verschaffel (2002).

A large extent of the students who participated in this research told that these kinds of real situations are not taught at school. On the other hand, a small percentage of them told that they are 
rarely mentioned but not emphasized too much. Some students supported that teaching these kinds of situations at school will confuse the students so they should not be taught at school. More than half of the students stated that they will like and enjoy mathematics more if these kinds of situations are taught.

Another finding obtained during the clinical interview is that wrong beliefs of the students about the obligation to make mathematical operations when a problem is asked in a maths class. When a problem is asked to them, they almost always make operations without questioning the problem if it can be solved or not. This finding is in line with the ones of Reusser and Stebler (1997) and Greer (1997). Reusser and Stebler (1997) expressed that students try to solve the question with the given numbers in the classroom atmosphere even if the question can not be solved or is absurd. The students try to solve the problem even if it has some incomplete information. The students think superficially about the problem and use the given numbers instead of thinking about it in a detailed way when word problems containing real-life situation are asked to them.

The students do not use their real-life knowledge too often while solving a problem. This shows that the students have difficulty in combining the knowledge they obtain from their experiences in their daily lives and mathematical knowledge that they obtain at school. This result shows similarity with the ones of Reusser and Stebler (1997), Verschaffel, De Corte and Lasure (1994) and Yoshida, Verschaffel and De Corte (1997).

The skills of students at the secondary part of elementary schools about mathematical word problem solving that require realistic answers and the percentage of giving realistic answers to those problems increase in direct proportion to their grade levels and skills of students at the secondary part of elementary schools about mathematical word problem solving that require realistic answers and the percentage of giving realistic answers are higher among the male students and also The percentage of giving realistic answers increase in direct proportion to the level of achievement in maths classes were found out at the end of this research.

In addition to that, it was seen that the students think that the problems that are asked in maths classes must have an accurate solution and these students who think that the mathematics and the real life are not related with each other thought about the realistic solutions but did not write them on the answers sheet.

In the first implementation done with 300 participants, the students made personal comments in the $11.6 \%$ of all answers given to the problem. The percentages of the realistic answers from the form consisting of the problems that contain the person were higher than the percentage of the realistic answers from the form consisting of the problems that contain only the information.

According to the results of the research, the suggestions which can be made about implementation are as follows:

The problem solving process in maths classes should be taught to the students in a more detailed way. Problem-solving and alternative problem-solving methods should be emphasized beginning from the primary part of elementary schools.

Various kinds of problems should be presented to the students. Presenting only routine problems is not enough. Although the new mathematics curriculum predicts that these kinds of problems should be presented and the students should be prepared for the real life, these kinds of problems are not seen in maths classes often. Polya (1957) indicates that routine problems are necessary for maths teaching; however, not presenting other kinds of problems to the students is an unforgiveable mistake. According to Polya, non-routine problems are the ones which leave a space to the students for imagination and judgement (quoted by Gürcan Töre, 2007). These kinds of problems should be used more often in maths classes. 
The importance of presenting problems that make the students consider their real-life situations and its benefits on the students should be explained to the teachers. Using these kinds of problems in classes will make a great contribution to maths teaching. Therefore, the students will realize the usage of the mathematics in their real lives, their fears about maths will decrease and they will not have difficulties when they see these kinds of problems in their real lives and will be able to get ready for the real life better.

In the problem solving process, it is necessary to make the students understand the problem instead of teaching the ways that take them to the solutions shortly. The efforts of the teachers to understand the problem solving processes of the students and their discussion on the solutions will provide the meaningful learning for the students. The solution of the problem and the applications of that problem in real life should be emphasized more.

This research was carried out with the 6 th, 7th and 8th grades of elementary schools. Carrying out a similar research with different grade levels and a larger sample will probably provide stronger information.

Besides, a study which investigates the opinions of the teachers and teacher candidates about the problems used in this research can be carried out. The opinions of the teachers about the usefulness of presenting these kinds of problems in maths classes can be collected with that kind of study. The awareness levels of the teachers can be increased.

An experimental study can be done to find out how the implementation of the problems in the solutions of which the real-life situations are considered influence the attitude and success of the students.

\section{References}

Akar, F. (2006). The efffectiveness of the discovery learning strategy on the mathematics achievement at the second step elementary. Unpublished master's thesis, Çukurova University, The Institute of Social Sciences, Adana, Turkey.

Altun, M. (2002). Maths teaching in 6th,, 7th and 8th classes, (2nd ed.). Bursa: Alfa Publishing.

Başar,M., Ünal, M. \&Yalçın, M. (2001). The reasons of the maths fear starting from the primary school. the congress of $v$. science and maths education. Retrieved August 10, 2007, from http://www.fedu.metu.edu.tr/ufbmek-5/b_kitabi/PDF/Matematik/Bildiri/t212d.pdf

Cooper, B. \& Harries, T. (2002). Children's responses to contrasting 'realistic' mathematics problems: Just how realistic are children ready to be mathematics. Educational Studies in Mathematics, 49, 123.

De Bock, D., Van Dooren,W., Janssens, D. \& Verschaffel, L. (2002). Improper use of linear reasoning: An in-depth study of the nature and the irresistibility of secondary school students' errors. Educational Studies in Mathematics, 50, 311-334.

Depaepe, F., De Corte, E. \& Verschaffel, L. (2010). Teachers' approaches towards word problem solving: Elaborating or restricting the problem context. Teaching and Teacher Education, 26, 152-160.

Dursun, Ş. \& Dede, Y. (2004). The factors affecting students' success in mathematics: Mathematics teachers' perspectives. Gazi University, The Journal of the Education Faculty, 24(2), 217-230.

Erden, M. (1986). Primary school 1st, 2nd, 3rd, 4th, and 5th graders' behaviours when solving problems based on four operations. Hacettepe University, The Journal of the Education Faculty, 1, 105-113.

Ersoy, Y. \& Gür, H. (2004). Maths teaching based on problem setting and solving approach - 1: Teachers' experiences and some problems. The board of mathematicians: The science corner. Retrieved July 17, 2007, from http://www.matder.org.tr/bilim/hgyepk.asp?ID=82 
Kamuran TARIM ve Sıdıka Pınar ÖKTEM - Çukurova Üniversitesi Eğitim Fakültesi Dergisi, 43(2), 2014, 19-38

Gainsburg, J. (2008). Real-worlds connections in secondary mathematics classrooms. Journal of Mathematics Teacher Education, 11, 199-219.

Greer, B. (1997). Modelling reality in mathematics classrooms: The case of word problems. Learning and Instruction, 7(4), 293-307.

Gür, H. \& Korkmaz, E. (2003). The identification of primary school 7th graders' problem development skills. The board of mathematicians: The science corner. Retrieved August 15, 2007, from http://www.matder.org.tr/bilim/i7sopoabb.asp?ID=38

Inoue, N. (2005). The realistic reasons behind unrealistic solutions: the role of interpretive activity in word problem solving. Learning and Instruction, 15, 69-83.

Inoue, N. (2002). The role of personal interpretation in mathematical problem solving. Columbia University.

National Council of Teachers of Mathematics. (2000). Principles and Standards for school mathematics, national council of teachers of mathematics. Reston, VA.

Reusser, K. \& Stebler, R. (1997). Every word problem has a solution - the social rationality of mathematical modeling in schools. Learning and Instruction, 7, 309-327.

Sevgen, B. (2002). The structure and the development of mathematical thought. The proceedings of $v$. national science and maths teaching congress ulusal fen bilimler. Retrieved August 10, 2007, from http://www.fedu.metu.edu.tr/ufbmek-5/b_kitabi/PDF/Matematik/Bildiri/t250DD.pdf

Soylu, Y. \& Soylu, C. (2006). The importance of problem solving in the way of achievement in maths classes. Inönü University, The Journal of the Education Faculty, 7(11), 97-111.

Verschaffel, L., De Corte, E. \& Lasure, S. (1994). Realistic considerations in mathematical modeling of school arithmetic word problems. Learning and Instruction, (4), 273-294.

Verschaffel, L., Greer, B. \& De Corte, E. (2000). Making sense of word problems. Lise: Swets and Zeitlinger.

Verschaffel, L., De Corte, E., \& Viersraete H. (1999). Upper elementary school pupils' difficulties in modeling and solving nonstandard additive word problems involving numbers. Journal for Research in Mathematics Education, 3(30), 265-285.

Umay, A. (2007). The new face of our old friend (1st ed.). Ankara: Aydan WEB Foundations.

Umay, A. (2003). The ability of mathematical reasoning. Hacettepe University, The Journal of the Education Faculty, 24, 234-243.

Xin, Z. \& Zhang, L. (2009). Cognitive holding power, fluid intelligence, and mathematical achievement as predictors of children's realistic problem solving. Learning and Individual Differences, 19, 124-129.

Yazgan, Y. \& Bintaş, J. (2005). Fourth and fifth grade students' level of problem solving strategies: A teaching experiment. Hacettepe University, the Journal of the Education Faculty, 28, 210-218.

Yoshida, H., Vershaffel, L. \& De Corte, E. (1997). Realistic considerations in solving problematic word problems: Do Japanese and Belgian children have the same difficulties? Learning And Instruction, 7, 329-338. 
